\title{
To Correlate Serum D-Dimer Levels With Clinical Outcome in Covid-19 Patients
}

\author{
Avinash Hanbe Rajanna ${ }^{1}$, Ravi K ${ }^{2}$, Vallish Shenoy ${ }^{* 3}$ \\ ${ }^{1}$ Assistant Professor, Department of Medicine, Bangalore Medical College and Research Institute, KR Road, \\ Bengaluru, Karnataka, India \\ ${ }^{2}$ Professor and HOD, Department of Medicine, Bangalore Medical College and Research Institute, KR Road, \\ Bengaluru, Karnataka, India \\ ${ }^{3}$ Junior Resident, Department of Medicine, Bangalore Medical College and Research Institute, KR Road, \\ Bengaluru, Karnataka, India
}

*Corresponding author: Dr. Vallish Shenoy; shenvoy55@gmail.com

Received 03 March 2021;

Accepted 26 March 2021;

Published 05 April 2021

\begin{abstract}
Background: The pandemic COVID19 has been causing significant morbidity and to some extent mortality as well. There has been urgent need to evaluate and identify the reliable predictors of disease severity and outcome. The fatal outcomes by COVID-19 are accompanied with micro vascular thromboembolism, which in turn is determined by serum D-dimer levels. Aim: To correlate serum D-dimer levels in COVID 19 patients admitted in an Indian setting, with clinical profiles and disease outcomes. Methods: A single-centre, observational, cross-sectional study was conducted among SARS-CoV-2 infected patients from March 2020 to May 2020. The diagnosis was confirmed by real-time polymerase chain reaction (RT-PCR). Serum D-dimer levels were compared with the treatment outcomes of the COVID-19 positive patients. Results: A total of 1977 COVID-19 patients were studied. The mean age was $43.89 \pm 15.58$ years and had male preponderance of $61.56 \%$ of the total subjects. The mean serum D-dimer levels among recovered and expired patients were $1.05 \pm 5.4 \mathrm{mcg} / \mathrm{ml}$ and $1.81 \pm 2.92 \mathrm{mcg} / \mathrm{ml} \mathrm{respectively}$. Conclusion: Serum D-dimer was increased in COVID-19 patients but did not show significant difference between the survival and the nonsurvival group, thus disproving it as a useful marker for assessing the severity of COVID-19.
\end{abstract}

Keywords: COVID-19, D-dimer, Thrombosis

\section{Introduction}

COVID-19 infection, which was first reported as a cluster of pneumonia from Wuhan, China in December 2019, has rapidly emerged as a global pandemic ${ }^{[1]}$. During the early course of the pandemic, Italy had the highest infection burden and India remained much less affected with corresponding mortality rates of $14.24 \%$ and $3.03 \%{ }^{[2]}$. The total cases in India has now crossed 11 million mark and officially confirmed deaths being 156,938, according to the Health Ministry data published on Feb 27, 2021 ${ }^{[3]}$.

Covid-19 is associated with high morbidity and mortality, leading to significant burden on healthcare infrastructure and resources. The associated death rate is also higher than any other respiratory viral infections. Hence, it is important to identify reliable predictors of disease severity and morbidity for careful allocation of healthcare resources and to ensure earlier clinical intervention, thus improving clinical outcomes.
Various biomarkers are being investigated for their role in the determination of severity and prognosis of COVID-19. Abnormal coagulation function, including elevated D-dimer, has been demonstrated to be common in deceased patients with COVID-19, and increasing odds of in-hospital deaths associated with D-dimer levels greater than $1 \mathrm{mcg} / \mathrm{ml}^{[4]}$. However, the association between D-dimer and the severity of COVID-19 is not yet clear.

In this study, we assessed the correlation between serum Ddimer and the severity and mortality of COVID-19 positive patients. We aimed to evaluate the serum levels of D-dimer and correlate it with the clinical outcomes.

\section{Methods}

This was an observational cross sectional study conducted among patients admitted under Medicine Department from March 2020 to May 2020 at Victoria hospital, Bangalore Medical College and 
Research Institute, Bangalore, Karnataka, India. Approval and clearance were obtained from the institutional ethics committee on 18/04/2020-BMCRI/PS/02/2020-21. The study included patients aged $\geq 18$ years of both genders, diagnosed with COVID-19 infection by RT-PCR technique using ABI/ThermofischerTaqppath technique. The study excluded patients $<18$ years of age and those not willing to provide signed informed consent prior to the study.

Case record form with follow-up chart was used to record the demographic data, duration and clinical features of the disease. Patient data like clinical symptoms and incidence of co-morbidities like hypertension, diabetes, renal, cardiac and respiratory disorders were noted. All the selected participants were followed up until outcome. Citrate blood samples were collected from all the patients and sent exclusively for serum D-dimer levels and later compared with the treatment outcome of all patients. The cut-off for D-dimer was $0.5 \mathrm{mcg} / \mathrm{ml}$, as per the hospital laboratory. The serum D-dimer level was determined by enzyme linked immuno-sorbent assay (ELISA) with iChroma 2 analyzer system. It was compared between the patients who survived and those who succumbed during their course at the hospital.

As per the first discharge policy released by the State Government, the patients were to be discharged after 14 days, if two consecutive throat/nasopharyngeal swabs taken $24 \mathrm{hrs}$ apart were negative for SARS-CoV-2 RNA done using RTPCR technique. If positive, test was repeated after $72 \mathrm{hrs}$. As per the revised discharge policy dated 26/05/2020, all mild and asymptomatic patients were to be discharged only after a repeat RT-PCR technique for SARS-CoV-2 RNA was negative, conducted 7 days after the first test. If positive, test was repeated after 72 hrs. As per the third discharge policy dated 23/06/2020, patients who had mild and moderate symptoms were to be discharged after 10 days without throat/nasopharyngeal swab test for COVID-19 and for severe patients, 14th day discharge policy based on negative swab test was adopted and those who were positive, the tests were to be repeated every 3rd day until obtaining a negative result. The demographics and clinical outcomes were then stratified and correlated.

Statistical analysis was carried out using software $\mathrm{R}$ version 3.6.0, 2019 Vienna, Austria. Continuous variables were expressed as mean and standard deviation and categorical variables were presented as counts and percentages. Patients were grouped as Survived and Death. Different parameters were compared between the groups using t-test for continuous and chi-square test for categorical data. $\mathrm{P}$ value $<0.05$ was considered statistically significant.

\section{Results}

The study considered 2000 patients admitted to Victoria hospital, Bangalore under Medicine Department and were diagnosed positive for COVID-19. Thirty-three patients were referred to other hospitals due to various reasons. Remaining 1977 patients were included in the study. All the patients were categorized as 2 Groups- Group 1: survived (1839-93.02\%) and Group 2: succumbed to death (138-6.98\%) based on the outcome observed. Among 1977 patients, 1419 (71.78\%), 128 (6.48\%) and 428 $(21.65 \%)$ were under 10 days asymptomatic policy, 2nd day swab discharge policy and 7th day swab policy respectively.

Table 1: Age distribution among the participants

\begin{tabular}{|l|l|l|l|l|}
\hline AGE & Total $(\mathbf{n}=\mathbf{1 9 7 7})$ & Survived $(\mathbf{n}=\mathbf{1 8 3 9})$ & Succumbed to death $(\mathbf{n}=\mathbf{1 3 8})$ & P value \\
\hline Age $($ years $)$ & $43.89 \pm 15.58$ & $42.74 \pm 15.15$ & $59.12 \pm 12.95$ & $<0.001$ \\
\hline Age Group & $419(21.19)$ & $418(22.73)$ & $1(0.72)$ & $<0.00001$ \\
\hline$<30$ years, $n(\%)$ & $452(22.86)$ & $443(24.09)$ & $9(6.52)$ & $18(13.04)$ \\
\hline $30-39$ years, $n(\%)$ & $369(18.66)$ & $351(19.09)$ & $43(31.16)$ \\
\hline $40-49$ years, $n(\%)$ & $356(18.01)$ & $313(17.02)$ & $40(28.99)$ \\
\hline $50-59$ years, $n(\%)$ & $238(12.04)$ & $198(10.77)$ & $27(19.57)$ & \\
\hline $60-69$ years, $n(\%)$ & $123(6.22)$ & $96(5.22)$ & & \\
\hline$\geq 70$ years, $n(\%)$ & &
\end{tabular}

Table 2: Gender distribution among the participants

\begin{tabular}{|l|l|l|l|l|}
\hline Gender & Total $(\mathbf{n}=\mathbf{1 9 7 7})$ & Survived $(\mathbf{n}=\mathbf{1 8 3 9})$ & Succumbed to death $(\mathbf{n}=\mathbf{1 3 8})$ & P value \\
\hline Male, $\mathrm{n}(\%)$ & $1217(61.56)$ & $1119(60.85)$ & $96(69.57)$ & 0.042 \\
\hline Female, $\mathrm{n}(\%)$ & $762(38.54)$ & $720(39.15)$ & $42(30.43)$ & \\
\hline
\end{tabular}

Table 3: Presenting symptoms among the participants

\begin{tabular}{|l|l|l|l|l|}
\hline Presenting symptoms & Total $(\mathbf{n}=1977)$ & Survived $(\mathbf{n}=1839)$ & Succumbed to death $(\mathbf{n}=138)$ & P value \\
\hline Asymptomatic, $\mathrm{n}(\%)$ & $941(47.80)$ & $924(50.24)$ & $17(12.32)$ & $<0.00001$ \\
\hline symptoms & & & & \\
\hline Fever, $\mathrm{n} \%$ & $600(30.35)$ & $532(28.93)$ & $68(49.28)$ & $<0.00001$ \\
\hline Dyspnea, n \% & $361(18.26)$ & $275(14.95)$ & $86(62.32)$ & $<0.00001$ \\
\hline Cough, n \% & $558(28.22)$ & $489(26.59)$ & $69(30.00)$ & $<0.00001$ \\
\hline Sore throat , n \% & $132(6.68)$ & $124(6.74)$ & $8(5.80)$ & 0.1842 \\
\hline Myalgia, , n \% & $207(10.47)$ & $192(10.44)$ & $15(10.87)$ & 0.8738 \\
\hline Head ache, , $\%$ & $19(0.96)$ & $1(0.72)$ & $18(10.98)$ & 0.7679 \\
\hline Others, $\mathrm{n} \%$ & $89(4.50)$ & $80(4.35)$ & $9(6.52)$ & 0.2354 \\
\hline
\end{tabular}


Table 4: Co-morbidity distribution among the participants

\begin{tabular}{|c|c|c|c|c|}
\hline Comorbidities & $\begin{array}{l}\text { Total } \\
(n=1977)\end{array}$ & $\begin{array}{l}\text { Survived } \\
(\mathrm{n}=1839)\end{array}$ & $\begin{array}{l}\text { Succumbed to death } \\
(n=138)\end{array}$ & P value \\
\hline None & $1105(55.89)$ & 1074(58.40) & $30(21.74)$ & \multirow[t]{6}{*}{$<0.00001$} \\
\hline Diabetes only & $118(5.97)$ & $110(5.98)$ & $8(5.80)$ & \\
\hline Hypertension only & $94(4.75)$ & $88(4.79)$ & $6(4.35)$ & \\
\hline Diabetes or Hypertension with other complications & $417(21.09)$ & $344(18.71)$ & $73(52.90)$ & \\
\hline Chronic Kidney disease & $25(1.26)$ & 17(0.92) & $8(5.80)$ & \\
\hline Other & $219(11.08)$ & 196(10.66) & 13(9.42) & \\
\hline
\end{tabular}

Table 5: Course in the hospital among the participants

\begin{tabular}{|l|l|l|l|l|}
\hline Course in the hospital & Total $(\mathbf{n}=\mathbf{1 9 7 7})$ & Survived $(\mathbf{n}=\mathbf{1 8 3 9})$ & Succumbed to death $(\mathbf{n}=\mathbf{1 3 8})$ & P value \\
\hline Oxygen requirement, $\mathrm{n}(\%)$ & $140(7.08)$ & $103(5.6)$ & $137(99.28)$ & $<0.00001$ \\
\hline ICU requirement & $264(13.35)$ & $126(6.85)$ & $138(100)$ & $<0.00001$ \\
\hline
\end{tabular}

Table 6: Comparison of serum D-dimer among different groups

\begin{tabular}{|l|l|l|l|l|}
\hline Laboratory parameter & Total $(\mathbf{n}=\mathbf{1 9 7 7})$ & Survived $(\mathbf{n}=\mathbf{1 8 3 9})$ & Succumbed to death $(\mathbf{n}=\mathbf{1 3 8})$ & P value \\
\hline D-dimer & $1.14 \pm 5.27$ & $1.05 \pm 5.4$ & $1.81 \pm 2.92$ & 0.248 \\
\hline
\end{tabular}

The demographic and clinical characteristics of the participants were noted. The average age of the participants were $43.89 \pm 15.58$ years and the mean age of survival and death noted were $42.74 \pm 15.15$ years and $59.12 \pm 12.95$ years respectively (Table 1 ). It was observed that participants of more than 50 years of age were less likely to survive (only $32 \%$ patients survived).

Out of 1977, patient male to female ratio was 1:0.62 showing male preponderance as shown in (Table 2).

Fever, dyspnea and cough were the major symptoms prevalent among patients who succumbed to death than in those who survived. In the mortality group, only $12 \%$ were asymptomatic, whereas it was around 50\% among survived subjects, (Table 3 ).

Comorbidities of the patients included in the study were noted as shown in (Table 4).

Out of 1977 patients admitted, 140 patients required oxygen, out of which 103 survived and 137 died. Also, 264 were admitted to ICU, where 126 patients survived, while 138 of them succumbed to the disease (Table 5).

Mean serum D-dimer among the participants who were included in the study was $1.14 \pm 5.27 \mathrm{mcg} / \mathrm{ml}$. It was found that, on an overall when compared to its cut-off, serum D-dimer was high in Covid-19 patients. Patients who succumbed to death did not differ much in their D-dimer levels when compared to those who survived, it being $1.81 \pm 2.92 \mathrm{mcg} / \mathrm{ml}$ and $1.05 \pm 5.4 \mathrm{mcg} / \mathrm{ml}$ respectively and was not statistically significant with $\mathrm{P}$ value of 0.248 (Table 6).

\section{Discussion}

At par with our findings, a study conducted by Saluja et al. in a tertiary Medical College, Rajasthan observed an increased male preponderance with majority being asymptomatic ${ }^{[5]}$. In our study, the male to female ratio was 1:0.62, which too showed male preponderance.

The present study has also demonstrated that the chances of survival are comparatively lower for patients more than 50 years of age. There is substantial literature evidence to validate the association between age-related COVID19 severity and mortality. A meta-analysis and rapid review by Starke et al. have also reiterated the positive associated between increased age-related risk of COVID-19 disease severity, admission to ICU and mortality. The increased risk per age year noted for disease severity was $2.7 \%$
[6]. Similarly, a meta-analysis involving 611,583 subjects have reported that the mortality was $<1.1 \%$ in subjects aged $<50$ years and the largest increase was observed in patients between the age group of 60-69 years, as opposed to 50-59 years ${ }^{[7]}$.

Our present study has noted fever, dyspnea and cough as the major symptoms prevalent among patients who succumbed to death when compared to those who survived ( $\mathrm{P}<0.00001)$. Zhang et al. have also evaluated the clinical characteristics of 82 deaths cases, laboratory-confirmed as SARS-CoV-2 infection. The researchers have reported fever (78.0\%), cough (64.6\%), and shortness of breath $(63.4 \%)$ as the prominent symptoms reported in the succumbed victims ${ }^{[8]}$.

A similar study by Gupta et al. conducted in a tertiary care centre in India, has also noted fever and cough (42.9\%) as the most prominent symptoms, followed by headache, sore throat, and breathlessness ${ }^{[9]}$.

In this study, it was found that serum D-dimer was $1.05 \pm 5.4 \mathrm{mcg} / \mathrm{ml}$ among the group which survived, compared to $1.81 \pm 2.92 \mathrm{mcg} / \mathrm{ml}$ in the group that succumbed to death, which was not statistically significant. But when compared overall, Covid-19 patients had elevated D-dimer of $1.14 \pm 5.27 \mathrm{mcg} / \mathrm{ml}$ in relation to its cut-off of $0.5 \mathrm{mcg} / \mathrm{ml}$. As a result, D-dimer levels can act as marker of Covid-19 but does not predict which patient might succumb to death.

In the current mortality group, around $53 \%$ of the subjects had diabetes/hypertension and around $6 \%$ of the subjects demonstrated chronic kidney disease as opposed to $0.92 \%$ in the survived group. A meta-analytic review focusing on developing countries including India reported that the presence of comorbidities is linked to poor outcomes in COVID-19 subjects. In concurrence with these findings, data from Mexico has also identified CKD, hypertension, COPD, obesity and diabetes are associated with elevated mortality risk in COVID patients ${ }^{[10]}$.

Zhang et al. studied the clinical characteristics of 82 cases of death due to COVID-19 which showed that most of the patients who died had co-morbidities, most common being hypertension $(56.1 \%)$ and more than half of them who died were more than 60 years old ${ }^{[8]}$.

The present study holds significance, as there is very limited literature evidence from the India correlating demographic data of COVID-19 patients with clinical profiles and disease outcomes. Moreover, it sheds light on several important findings, which would help physicians in screening, treatment decision and 
prognosticating. Another usefulness of our study is good sample size, but the generalization of the findings is limited, as the study was carried out in a single centre. Our study has not evaluated the outcomes from treatment interventions. This was not considered, as no specific standard protocol was available at that point of pandemic for managing COVID-19 patients.

Recent studies documenting the laboratory changes of patients with confirmed COVID-19 have noted that elevated Ddimer might be associated with the disease progression of COVID19 suggesting deep vein thrombosis and pulmonary thromboembolism. The level of D-dimer in patients with COVID19 admitted to the ICU was reported as significantly increased ${ }^{[12]}$. In addition to thrombosis and pulmonary embolism, Ddimer might also be a manifestation of severe Covid-19 infection. A virus infection may develop into sepsis and induce coagulation dysfunction, which is common in serious disease progression. Moreover, the increase of D-dimer may be an indirect manifestation of inflammatory reaction, as inflammatory cytokines might cause the imbalance of coagulation and fibrinolysis at the alveoli, which may activate the fibrinolysis system, which might in turn increase the level of D-dimer ${ }^{[13]}$. Our study also showed that Covid-19 patients had elevated D-dimer levels but did not statistically show any difference between survivor and nonsurvivor group. One of the limitations of this study was the nonuniformity of sample collection and processing time due to increased case load in a resource-limited environment. Nonetheless, our study showed that D-dimer level more than 0.5 $\mathrm{mcg} / \mathrm{ml}$ can act as a marker of Covid-19 infection in a pandemic setting.

\section{Conclusion}

Increased levels of Serum D-dimer were observed among most COVID-19 patients, but Serum D-dimer did not help in differentiating outcomes among the COVID-19 patients who could not survive the treatment when compared to the recovered patients. Therefore, serum D-dimer levels could be used as a screening marker in the diagnosis and management of COVID-19 patients, which can be made available across hospitals in the subcontinent.

\section{Declarations}

\section{Ethical approval}

Approved- BMCRI/PS/02/2020-21

\section{Funding}

None

\section{Conflict of interest}

None

\section{References}

[1] Pneumonia of unknown cause - China [Internet]. World Health Organization. 2021 [cited 2021 Feb 27]. Availablefrom:https://www.who.int/csr/don/05-january2020-pneumonia-of-unkowncause-china/en/

[2] COVID-19 Mortality Trends and Reporting [Internet]. Economic and Political Weekly. 2021[cited2021 Feb 27]. Available from:https://www.epw.in/journal/2020/37/commentary/c ovid-19-mortality-trends-and-reporting.html

[3] MoHFW. [Home] [Internet]. Mohfw.gov.in. 2021 [cited 2021 Feb 27]. Available from: https://www.mohfw.gov.in

[4] Tang N., Li D., Wang X. Abnormal coagulation parameters are associated with poor prognosis in patients with novel corona virus pneumonia. J. Thromb. Haemost. 2020;18(4):844-847. doi: 10.1111/jth.14768.

[5] Saluja M, Pillai D, Jeliya S, Bauddh N and Chandel R. COVID 19-Clinical Profile, Radiological Presentation, Prognostic Predictors, Complications and Outcome: A Perspective from the Indian Subcontinent. J Assoc Physicians India. 2020;68(7):13-18.

[6] Romero Starke K, Petereit-Haack G, Schubert M, Kämpf D, Schliebner A, Hegewald J, et al. The Age-Related Risk of Severe Outcomes Due to COVID-19 Infection: A Rapid Review, Meta-Analysis, and Meta-Regression. Int J Environ Res Public Health.Int J Environ Res Public Health. 2020 Aug; 17(16): 5974.

[7] Bonanad C, García-Blas S, Tarazona-Santabalbina F, Sanchis J, Bertomeu-González V, Fácila L, et al. The Effect of Age on Mortality in Patients With COVID-19: A Meta-Analysis With 611,583 Subjects. Journal of the American Medical Directors Association. 2020 Jul 1;21(7):915-8.

[8] Zhang B, Zhou X, Qiu Y, Song Y, Feng F, Feng J, et al. Clinical characteristics of 82 cases of death from COVID-19. PLOS ONE. 2020 Jul 9;15(7):e0235458.

[9] Gupta N, Agrawal S, Ish P, Mishra S, Gaind R, Usha G, et al. Clinical and epidemiologic profile of the initial COVID-19 patients at a tertiary care centre in India. Monaldi Archives for Chest Disease. 2020 Nov 3;90(1).

[10] Singh AK, Misra A. Impact of COVID-19 and comorbidities on health and economics: Focus on developing countries and India. Diabetes Metab Syndr. 2020;14(6):1625-30.

[11] Huang C., Wang Y., Li X. Clinical features of patients infected with 2019 novel corona virus in Wuhan, China. Lancet. 2020;395(10223):497-506. doi: 10.1016/s01406736(20)30183-5.

[12] Tang N., Bai H., Chen X. Anticoagulant treatment is associated with decreased mortality in severe corona virus disease 2019 patients with coagulopathy. J. Thromb. Haemost. 2020 doi: 10.1111/jth.14817. 